\title{
Enlightenment of Kohlberg's Theory of Moral Development in the Context of Moral Education in Mainland China
}

\author{
Qian Zhang \\ School of English and Education, Guangdong University of Foreign Studies, Guangzhou, China \\ Email: gwzhangqian@126.com
}

How to cite this paper: Zhang, Q. (2019) Enlightenment of Kohlberg's Theory of Moral Development in the Context of Moral Education in Mainland China. Open Access Library Journal, 6: e5737. https://doi.org/10.4236/oalib.1105737

Received: August 26, 2019

Accepted: September 21, 2019

Published: September 24, 2019

Copyright $\odot 2019$ by author(s) and Open Access Library Inc.

This work is licensed under the Creative Commons Attribution International License (CC BY 4.0).

http://creativecommons.org/licenses/by/4.0/

\begin{abstract}
Kohlberg's theory of moral cognitive development is quite influential, widely applied in practice by moral theorists and educators all over the world. It is proved to be very effective. The current moral education in the mainland of China is characteristic of low efficiency. This paper intends to analyze the causes of this low efficiency after the reforming and opening policy was adopted in China and to tentatively give some suggestions to improve this situation.
\end{abstract}

\section{Subject Areas}

Education, Sociology

Keywords

Morality, Moral Cognitive Development, Moral Education

\section{What Is Morality?}

In the long river of history, philosophers and ethicists in the East and West, never stop asking the question: What is goodness?

Socrates claimed that goodness is knowledge. Wisdom (knowledge) benefits people. All the efforts and talents, if guided by wisdom, will definitely lead to happiness. If not, will lead to disasters. Therefore, one with normal mind will doubtlessly do what he believes is correct. Man does the good if he knows what is goodness. By emphasizing the rationality of goodness, Socrates correctly points out the relationship between morality and knowledge, confirming the "teachability" of morality. However, he equates goodness with knowledge, un- 
ilaterally emphasizing the function of objects, ignoring the subjects-human. As a live man, besides knowledge, he has a lot of subjective emotions like inner tendency, motivation, emotion, attitude and willingness. If goodness is only the knowledge which can be conveyed in the classroom, it must be correct that a better-educated person must be a noble one and a poorly-educated person must be a mean one. However, in the real life, the fact is more often the contrary. That is why Socrates' view about goodness is attacked by scholars.

Aristotle inherited Socrates' view of goodness and further developed it by insisting that goodness is acquired in real life, instead of teaching. Just like swimming, one can never learn how to swim unless he observes the demonstration and practices by himself in the water. Similarly, one can be a just man only by doing justice; an honest man only by fitting his deeds to his words; a considerate man only by practicing tolerance.

Therefore, the same with skills, the first and foremost factor for goodness is not the teaching and learning of knowledge, but the cultivation and acquisition of behaviors and habits. Goodness can be taught via demonstration, training and practice, instead of conveyance of the knowledge in the classroom.

Kant believed that the kind will is the foundation of morality, illustrating moral (widespread) formal feature, and showing human subject characteristic as to achieve "the (Copernicus) revolution" in ethics. He insists that morality has nothing to do with man's emotions. For example, when one finds his neighbor in danger, he should offer his help whether he likes or not. A teacher must be responsible with his students whether he likes or not. A doctor must try all his best to save his patients whether he likes or not.

Whatever view is mentioned above, whether it is Socrates's knowledge view, Aristotle's skill view, or Kant's goodwill view, they all have something in common. That is, they all take rationality as the core of moral education, excluding emotional factors.

Since 1960s, there emerged moral cognitive-developmental theory initiated by Piaget and greatly developed by Kohlberg. This theory absorbs the reasonable parts of various views on morality and combines moral emotions with moral cognition. It argues that, first of all, since man, in essence, is rational, man can only know morality through wisdom, and that is exactly the basis to set up moral principles and regulations. Therefore, morality is not only teachable but also acquirable via teaching.

Secondly, man's moral rationality is not born by nature or inculcated from the outside, instead, it is the outcome of the interaction between the subject and the object. Therefore, it is quite important to emphasize the interaction between individual's cognitive development and social objects.

Thirdly, it is the major target of moral education to emphasize the function of the subjects and to cultivate the individual's moral cognitive competence (that is, moral judgment, including moral understanding and moral judgment competence and moral character). Lastly, by emphasizing the developmental process of 
the individual's moral cognitive competence, we mean to devise the curriculum of school education according to the requirements of the development of moral cognitive competence and to choose appropriate contents and methods of teaching morality.

This theory clearly points out, firstly, morality is "teachable" because of the rationality of moral principles and regulations; secondly, moral rationality is highly contextualized, which can and only can acquire through moral practice instead of indoctrination; thirdly, moral education has to be taught according to the development of moral cognition; fourthly, moral cognition is equal to moral judgment.

Although this theory is criticized for its over-emphasis of moral cognition in individuals' moral development, it points out that individuals' moral cognition has the stage characteristics and laws, and that it is a "naturally formed" process of interaction between individuals and the specific moral contexts. This view is of significance in guiding the current moral education, bettering the current educational system and improving the students' moral cognitive competence.

\section{Low Efficacy of Moral Education in China and Its Causal Analysis}

When we take a look at the school moral education in current China, it would be quite obvious to see that teachers are still used to instilling the moral regulations and rules to the students and students are the passive listeners. This situation is closely related to the mode of social control in China in the past years.

Before the reforming and opening up policy was carried out in 1978, China adopted highly-controlled planning system in economy and completely closed system in politics. In that case, people were ruled by a top-to-bottom authoritative thoughts and lack of self-identity or independent thoughts. The function of moral education in schools is to teach students systematic and logical knowledge; the purpose of moral education in schools is to instill students the values that are consistent with the mainstream ideology in China; the task of moral education in schools is to preserve the current educational system. At that moment, the social environment was comparatively simple, people's thoughts were tending to be the same, and there were no big social conflicts. Therefore, the enclosed moral education in schools could be consistent with the mode of social control.

However, since the reforming and opening up, especially in the past twenty years, there was further transformation in politics, economy and culture in China, which gave rise to huge changes in Chinese society.

Firstly, there appeared various social groups with different economic interests and different value orientation. Inevitably, they interact with each other, clash with each other, even conflict with each other. At the same time, with the development of social productivity, people's democratic awareness was strengthened, therefore, the conflicts mentioned above could not be solved by the inculcation 
of the moral theories and rules. Secondly, in the $21^{\text {st }}$ century which is characterized by rapid development in information technology, different values and legitimate interests are spreading nationwide more widely, rapidly and transparently. Information can no longer be controlled by one single authority and the mainstream criterion is no longer the only acceptable one. Therefore, the attitude towards the values different from the mainstream ones has also changed from absolute rejection and denial to acceptance to their reasonable components.

Based on the previous two points, there also appeared great changes in people's mind. People get more initiatives in working out solutions to the new moral problems in the new era. Apparently, the old moral values and regulations are outdated and need to give way to the new ones. People start to question the mainstream values, to discuss the phenomena that are challenging the old values, and to judge and make a choice of the different approaches and theories.

However, when people's mind starts to be more and more open, moral education in schools is far behind the social development pace in the following aspects:

Firstly, narrowness of the subjects of moral education in schools.

Schools and teachers are still the subjects of moral education, and students are the passive recipients without self-determination, self-choosing and independent judgment.

Students are regarded as the unconditional followers of the given moral values and regulations, who have no right to question their reasonability nor putting forward new regulations and principles in moral education. This awkward situation is contradictory with the characteristics of the students living in the new era, who are more independent in thoughts, stronger awareness in participation and more eager to voice their own opinions, claim their rights and more reluctant to accept the old values and regulations passively.

Secondly, the closeness of the teaching contents. The opening up policy gives the access to market economy. Globalization brings about not only pluralistic economy, but more importantly, pluralistic politics and culture, thoughts and minds. Market economy advocates for the pursuit for individuals' interests in a reasonable way and for the cultivation of personality. However, the current moral education is still confined in the past traditional thoughts, overemphasizing collective interests and generality, depriving people of their chance for personal development, which is not consistent with the requirements of the changed mode of economic development. In Durkheim's words, it is "the conflict between people's pursuit for their personal values in market economy and the moral criteria or principles which too much emphasize collective interests and general nature". Market economy brings about new ideas and thoughts inconsistent with the traditionally mainstream thoughts, which exerts a great impact on the traditional views on moral education in Chinese schools, as well as challenge for Chinese traditional culture and concepts.

Secondly, the oneness of educational methods. The current moral education is still adopted in the way of classroom teaching and the instilling of knowledge. It 
emphasizes the mastery of basic theoretical knowledge while ignoring the individual interests and needs of the students. Morality becomes the cold words in the textbooks, and teachers become the judges of the students' behaviors, instiller of regulations and the authority of social will. Students are deprived of participating into the moral education process, and become the passive receiver of moral knowledge.

With the development of the society, what the students were taught before contradicts with the social reality and fails to explain the new social problems and social phenomena. In that case, students have some doubts about what they learned before in the classroom, which is quite natural and to some extent, is good because the conflicts are helpful for people to learn morality and to get improved.

Frank Thilly said, "Morality is the result of the contradiction of individual interests. If there is no contradiction in the life, there is no need for moral regulations." [1] However, in the current classrooms, teachers do not pay due attention to the conflicts between people and people, people and the society, which fails to make the moral lessons close to the real life and therefore makes moral education meaningless [2].

What's more, the increasingly changed society requires teachers to deepen their understanding of moral problems. In fact, they actually are facing common doubts with the students which need to be clarified through discussions. The enforced indoctrination and outside educating can do nothing but damage to the effect of moral education.

\section{Means to Increase the Inefficacy of Moral Education in China}

As Kohlberg said, moral sensibility of human beings is the interaction of subjects and objects in practice. Different from other scientific knowledge, moral character cannot be measured by the mastery of abstract knowledge. Moral cognition cannot automatically give rise to moral competence. Therefore, one with abundant moral knowledge may not necessarily be moral. Lind pointed out that moral judgment competence is a bridge between moral cognition and moral behaviors, and that a good way to develop one's moral judgment competence is through the practice of subjects, instead of indoctrination from outside.

In order to change the inefficacy of the current moral education in China, schools should take the major responsibility by leading moral education into the real life and the specific contexts, encouraging students to get involved actively, to conduct discussions about the moral issues in the society, to clarify their doubts and put forward their ideas [3] [4]. Only when moral regulations are virtually accepted by people, can they be rooted into their mind.

Researches both in China and abroad have shown that school moral atmosphere has exerted a great influence on students' moral competence and norm behaviors. 
In 1970s, Kohlberg, for the first time, put forward and then gradually formed the idea of group moral atmosphere based on his Just Community [5]. He believed that, in schools characteristic of just community, students, teachers and administrators should work together to make rules, take responsibility as well as obligations to abide by and maintain them, which aims to create a kind of school atmosphere beneficial for individuals' moral development [6].

More and more scholars and researchers get to realize the fact that the school moral atmosphere is helpful for improving students' moral awareness and moral behaviors, and that the extent to which the students perceive school moral atmosphere will greatly affect his moral judgment competence and moral behaviors [7].

The Dutch scholar Brugman, with his "school moral atmosphere" scale, conducted a series of researches about school moral atmosphere, which reveals that students' perception of moral atmosphere varies significantly from schools to schools. What's more, there exists a significant relationship between school moral atmosphere and students' moral competence.

Qiming Li, a scholar from Taiwan, translated Brugman's questionnaire into Chinese and conducted a research on the moral atmosphere in Taiwan's junior school students and primary school students, which revealed that students' perception of the school moral atmosphere varied from school to school.

Weiqing Li, from the mainland of China, developed a questionnaire and his research revealed that the student's perception of school moral atmosphere greatly affects their moral awareness and moral judgment competence. Teachers help to develop the students' perception and moral judgment competence through contextual discussion and role-play [8].

The researches in psychological field have given us very important enlightenment, that is, the effective way to improve students' perception of school moral atmosphere is to make students accept with full heart the moral regulations and moral ideas. Only in this way, can those regulations be internalized and fully accepted by the students [9].

Therefore, as moral educators, we should be open-minded, democratic and reflective in our teaching.

Firstly, being open-minded. Who is the subject of moral education? We used to take schools and teachers as the subjects of moral education, take moral education as inculcation of all moral principles. In that way, students become passive receptors and unconditional conformers of moral orientation and moral principles. Students can only receive rather than refuse, can only believe rather than doubt, can only conform rather than make a choice.

Being open-minded means that schools and the organizations related to moral education should take students into the scope of subjects of moral education and develop their initiatives to get involved into moral education. At the same time, the educators should regard the given moral orientation and moral principles as an open system, instead of a set of rigid and changeless regulations. We should 
let students throw their doubts about the given moral regulations, guide them to take part in moral practice in which they can test moral regulations and then supplement with them, even change them with the social changes.

Secondly, being democratic. It means that both schools and teachers should treat students in a democratic atmosphere, adopting a kind of discussing way instead of lecturing. We should equally treat students in both study and life, respecting the individual differences, listening to their ideas and making a choice of their own, instead of forcing students to accept the moral precepts and moral stance. We should invite students to get involved into the activities to change and reflect on, rather than regard them as the passive receptors of the given moral disciplines.

As for what is against the moral principles and regulations in the society, teachers should discuss with the students in an equal and democratic way, encouraging students to think and reflect independently. Teachers are no longer the judges, instead, they are the guides. Only in a democratic atmosphere, in a democratic way, can the students be motivated to accept moral education with their full heart. And only in that case can moral education be internalized.

Thirdly, being reflective. It means that schools and teachers should reflect on both the moral education practice and the current moral principles and moral orientation. With the social development, there have been a lot of changes which calls for new interpretation, even reformation for the current moral principles. Some traditional moral principles which were in mainstream in the past are no longer consistent with the requirements of the new society, while on the contrary, some moral principles which were off mainstream consist of some reasonable components consistent with the social development, all of which ask for the reflection of schools and teachers on the contents and methods of moral education in China.

\section{Conflicts of Interest}

The author declares no conflicts of interest regarding the publication of this paper.

\section{References}

[1] Thilly, F. (1987) Overview of Ethics. China People's University Press, Beijing, 176-177.

[2] Lu, J. (2000) Book on Moral Edcuation. Nanjing Normal University Press, Nanjing.

[3] Wan, Z.K. (2009) Psychological Studies on Moral Identity. Shanghai Education Press, Shanghai.

[4] Yang, S.G. (2007) New Findings of Western Moral Psychology. Shanghai Education Press, Shanghai.

[5] Kohlberg, L. (2004) Moral Development Psychology. East China Normal University Press, Shanghai. (Translated by Guo, B.Y., et al.)

[6] Qiu, Y. (2009) Enlightenment of Kohlberg's Moral Development Theory on Moral Education. Laws and Society, 11, 17-23. 
[7] Wang, H.J. (2009) Kohlberg's Moral Cognitive Theory on Moral Education in China. China Science and Education Innovation Guide, 35, 23-30.

[8] Shi, Y. (2009) Kohlberg's Cognitive Theory and Its Influence on Chinese Moral Education. Journal of Liaoning Institute of Educational Administration, 7, 78-82.

[9] Wang, F.Z. (2009) From Inculcation to Face-to-face Talk: A Transfer of Modern Education in Moral Education. Teaching and Managing, 3, 77-82. 